\title{
THE TEACHING OF THE ARCHITECTURE PROJECT: NEW METHODOLOGICAL ASPECTS
}

\author{
M.I. Alba Dorado \\ University of Málaga (SPAIN) \\ maribelalba@uma.es
}

\begin{abstract}
At the beginning of the new millennium, the construction of the so-called European Higher Education Area has set us the search for answers to the challenges of a globalized world characterized by its accelerated dynamism and a knowledge society in continuous evolution and with multiple access tools to the information you need from professionals with new skills and abilities.
\end{abstract}

So that all this makes inevitable that the teaching of architecture in Spain is positioned in front of the new approaches, benefits and considerations that European society demands for the XXI century by defining strategies and mechanisms of continuous reflection that will lead it to adapt to the new changing situations and to do it also, from the quality and the excellence.

Therefore, it is necessary to develop more flexible learning pathways to support permanent learning, as well as to reconsider the ways of teaching and learning in the Schools of Architecture, attending not only to what is to be taught, but also to how it is going. to teach with the aim of moving from the traditional model of transmission of knowledge from the teacher to the student, to a model based on the development of competences in the student that makes him become the true protagonist of his own education.

The teaching of architecture should be oriented to the creation of learning situations, to facilitate, encourage and stimulate autonomous learning, motivating and encouraging the student in his search for architecture, guiding, guiding and tutoring him academically.

Likewise, this teaching should be conceived as a continuous research that participates in an open, flexible and dynamic disciplinary discourse that incorporates the instruments and contributions of a world in continuous transformation. In this sense, it is necessary to outline a new teaching model for higher education, flexible and that allows a more critical and deep intellectual development that enables to generate knowledge. Thus, a teaching is demanded in which the training on information predominates with the aim of creating learning situations that facilitate a subsequent continuous training.

This refers to a formative teaching, to a teaching of architecture focused more on teaching an attitude, a disposition towards the project, which has as its objective the training of the student rather than the accumulation of objective knowledge.

In this sense, the university professor is required to, on the one hand, rethink his teaching function, orienting it towards the creation of learning situations that facilitate and stimulate autonomous learning beyond the transmission of knowledge but, on the other hand, he is asked to reconsider its investigative function in an area in which competitive research and the creation of multidisciplinary teams are encouraged. Thus, the profile of the university professor can not be separated from the two major professional functions he must assume: teaching and research. Both, in addition, must be considered in a complementary manner. Therefore, only one who is trained in research, who cares to investigate, will continue to create knowledge and incorporate new contributions in their 
field, in short, those who care about their own training on a permanent basis and develop a critical capacity and a constant attitude of reflection and self-improvement.

This change in the teaching model also makes it necessary to rethink the role of the student, who must participate in a much more active way in the learning process than he currently does. All this leads us to talk about continuous training that will accompany the student throughout his life and that refers to a learning of architecture in which different knowledge and skills acquired over time converge. 